\section{A new journey}

My recent appointment as Deputy Editor 5 months ago has afforded me the opportunity to observe, and be involved in, the editorial process.

My initiation into the publishing of scholarly journals was marked by a visit to the Health and Medical Publishing Group (HMPG) office in Rondebosch, Cape Town, where I was introduced to the publishing team responsible for delivering the completed journal, in print and online, to the radiology community each quarter. HMPG publishes not only the South African Journal of Radiology (SAJR), but also the South African Medical Journal (SAMJ), the Journal of Continuing Medical Education (CME) and the official journals for a number of specialist societies. Accessing the HMPG webpages allows the researcher access to the full stable of journals, current and past. Advances in information technology have inter alia resulted in an online manuscript management system, which has revolutionised the submission and review process, improving the reviewing and editing interface for all journals. I take this opportunity to acknowledge the efforts of a talented and committed team.

As part of my continuing editorial education, I attended the 6th annual meeting of the National Scholarly Editor's Forum (NSEF) of South Africa, convened at Belmont Square Convention Centre, Cape Town, on 25 July 2012. The diverse topics on the agenda were informative, and I share a selected few in this editorial.

The NSEF is a consultative and advisory body managed by the Academy of Science of South Africa (ASSAf). ASSAf was inaugurated in May 1996 by former President Nelson Mandela, and officially represents the country in the international community of scientific academies. It includes distinguished scientists from diverse fields. In 2008, ASSAf adopted and approved the National Code of Best Practice in Editorial Discretion and Peer Review for South African Scholarly Journals. The fundamental principles of research publishing, the core role of editors, and the indispensable task performed by peer reviewers, were included.

Colleagues employed in challenging fulltime academic positions, who accept the task as editor in the absence of financial incentives, receive alternative rewards that include continuing education and networking opportunities. The essential requirement is for responsible editorial supervision, ensuring that an editorial policy exists and is accessible to authors. It is pertinent to mention that, although the SAJR is in the position to publish suitable material that has passed a peer review process, it is not an examining body. The SAJR has received requests to review manuscripts, submitted as case reports, for the purposes of meeting the research requirements of the Master of Medicine (MMed) degree. The hierarchy of scientific data dictates that a case report has a lower level of scientific impact. To maintain a high standard for the Master of Medicine Degree in Radiology, the submitted manuscripts, intended for degree purposes, should have a high scientific impact and undergo peer review by highly regarded university academics.

Selected peer reviewers, as suggested by the National Code of Best Practice, must have the expertise and specialised knowledge pertaining to the topic addressed in a submitted paper if they are to complete their role in the system of universal knowledge accumulation. For the SAJR to publish manuscripts of highest quality, we require the continued, and valued, support of those individuals in the South African radiology community who are experts in their respective radiological disciplines.
MMed students should be encouraged to distribute their scholarly research through journal publication. Strong mentorship, constructive criticism and commitment to publication are key elements for preparing a manuscript for publication. To receive subsidy or recognition for an article, an author should select a journal that is accredited. Accredited journals are recognised research publications that meet specific criteria and therefore qualify for financial subsidy by the Department of Higher Education and Training (DHET).

Lists acknowledged by the DHET include the ISI (Institute of Scientific Information), the IBSS (International Bibliography of Social Sciences), Accredited Open Access Journals, and the Approved South African Journal List. The Thomson Reuters Institute of Scientific Information (ISI) Web of Science database contains just over 12200 journals. Although all subject fields are covered, over 8000 are in the sciences. The IBSS list contains fewer than 2800 journals and focuses on the social sciences. The DHET list contains approximately 250 South African journals in various subject fields. The SAJR is accredited by the DHET.

However, problems encountered with ISI and IBSS, which include non-listing of top journals in certain fields, extensive coverage of certain academic fields above others, and non-transparency of the listing process, have been reported. The DHET has therefore recommended that the ISI, IBSS and SA Approved List be retained and the Norwegian list and SciELO South Africa be considered.

SciELO SA (Scientific Electronic Library online South Africa) is an integral part of the SciELO portal, which had its origins in Brazil and is now distributed across most South American countries. Editors at the 6th NSEF meeting in July 2012 were informed that, as of April 2012, SciELO SA had been independent from SciELO Brazil. It is a national open access database managed by the ASSAf, funded by the South African Department of Science and Technology, and endorsed by the DHET. It is hoped that SciELO SA will strengthen the scholarly journal evaluation and accreditations systems in South Africa.

In addition, editors were informed that ASSAf and the DHET were prompted to review the journals on the SA list after concerns were raised regarding the quality of several listed journals. The proposed recommendation is that a journal will only be listed for 5 years. This would provide the time necessary to develop the journal to international standards and to apply for listing on any of the accredited indices. Journals removed after this 5-year period would be able to re-apply after a minimum of 2 years, but evidence that the journal had been published uninterrupted for a minimum of 3 years, would have to be submitted.

I experienced the diverse matters tabled for discussion at the 6th annual NSEF meeting as an enlightening education. The last 5 months have been an interesting journey. I hope to be involved in many more successful volumes of the $S A J R$, and encourage its continued support and participation from the South African radiology community. Thank you for this opportunity.

\section{Razaan Davis}

Deputy Editor 